\title{
A coping and communication support intervention tailored to older patients diagnosed with late-stage cancer
}

\author{
Julia Hannum Rose $e^{1,2,3}$ \\ Rosanne Radziewicz ${ }^{4}$ \\ Karen F Bowman ${ }^{5}$ \\ Elizabeth E O'Toole' \\ 'Case Western Reserve University \\ School of Medicine, Cleveland, $\mathrm{OH}$, \\ USA; ${ }^{2}$ Louis Stokes Cleveland VAMC- \\ GRECC, Cleveland, OH, USA; ${ }^{3}$ Center \\ for Health Care Research and Policy, \\ Case at MetroHealth Medical Center, \\ Cleveland, OH, USA; ${ }^{4}$ Department of \\ Nursing, MetroHealth Medical Center, \\ Cleveland, OH, USA; ${ }^{5}$ Department \\ of Sociology, Case Western Reserve \\ University, Cleveland, OH, USA
}

\begin{abstract}
As our society ages, increasing numbers of older Americans will be diagnosed and eventually will die of cancer. To date, psycho-oncology interventions for advanced cancer patients have been more successful in reaching younger adult age groups and generally have not been designed to respond to the unique needs and preferences of older patients. Theories and research on successful aging (Baltes and Baltes 1990; Baltes 1997), health information processing style (Miller 1995; Miller et al 2001) and non-directive client-centered therapy (Rogers 1951, 1967), have guided the development of a coping and communication support (CCS) intervention. Key components of this age-sensitive and tailored intervention are described, including problem domains addressed, intervention strategies used and the role of the CCS practitioner. Age group comparisons in frequency of contact, problems raised and intervention strategies used during the first six weeks of follow up indicate that older patients were similar to middle-aged patients in their level of engagement, problems faced and intervention strategies used. Middle-aged patients were more likely to have problems communicating with family members at intervention start up and practical problems as well in follow up contacts. This is the first intervention study specifically designed to be age sensitive and to examine age differences in engagement from the early treatment phase for late-stage cancer through end of life. This tailored intervention is expected to positively affect patients' quality of care and quality of life over time.
\end{abstract}

Keywords: aging, psycho-oncology interventions, advanced cancer, supportive care

\section{Introduction}

This paper describes our development of a coping and communication support (CCS) intervention for advanced cancer patients. Key components of this age-sensitive and tailored intervention are described, including problem domains addressed, intervention strategies used and the role of the CCS practitioner. Preliminary data on similarities and differences in middle-aged and older patients' initial problems, preferences and engagement in the intervention are reported. Although family caregivers are an integral part of our intervention study, this article reports only on patients. The CCS intervention is implemented with newly diagnosed late-stage cancer patients who are middle-aged and older. It is tailored to patients' needs and preferences and designed to support them over the period of time when life goals and care goals are expected to shift. The intervention is informed by three theoretical frameworks. First, based on a model of successful aging over the lifespan (Baltes and Baltes 1990; Baltes 1997), the intervention offers patients ongoing coping and communication support to facilitate selective optimization with compensation that may effectively maintain and achieve evolving goals. Second, recognizing the importance of health information processing style in cancer communication (Miller 1995; Miller et al 2001), the intervention takes into account patients' propensities to monitor and blunt against threatening health information. Third and last, 
understanding that most middle-aged and older patients have faced previous life stressors, the intervention assumes that most patients in these mature age groups will be responsive to a non-directive client-centered approach to intervening (Rogers 1951, 1967).

\section{Aging and advanced cancer}

The incidence of cancer is rising and occurs with greater frequency throughout the middle and later years (Yancik 1997; ACS 2006). It is the leading cause of death among women in their forties and fifties and the second leading cause of death for men in this age group (Merrill and Verbrugge 1999). The prevalence of cancer is highest among adults over age 60 and has now replaced heart disease as the leading cause of death among older adults in their sixties and seventies (Extermann 2002). Age is an important factor in communication and medical decision making in both hospital (Hamel et al 1999; Coe and Miller 2000; Rose et al 2000, 2004) and communitybased settings (Siegler and Levine 2000; Balducci and Beghe 2002). For patients with advanced cancer, decision making often occurs within "palliative care". The objective of palliative care is to optimize quality of life and manage symptoms rather than to cure, but its treatments may range from invasive measures that can prolong life to measures assuring comfort, regardless of effect on life extension (Cleary and Carbone 1997; Esper et al 1999).

The context of when in the life span a diagnosis of cancer occurs has major implications for patients in terms of distress, coping, and communication problems (Ganz et al 1985; Rose 1991, 1993; Filipp 1992; Rose et al 2004). The potential need to facilitate and advocate for the expression of care needs and assure implementation of preferences has been shown differ for older cancer patients (Nussbaum et al 2003; Rose et al 2004). Many older adults look forward to continued years of independence, yet with advancing age the majority must cope with growing limitations in physical and cognitive functioning as well as the loss of loved ones. At the same time, older adults may be more reticent to become actively involved in medical treatment decision making (Haug and Ory 1997; Adelman et al 2000). Terminal cancer in middle-aged adults often brings other challenges for patients, especially as children approach adulthood and/or older parents require assistance. Such different circumstances have significant effects on coping and decision making for patients. Concerns about aging and the personal burden of treatment (Balducci and Beghe 2002) as well as about the potential use of age as a criterion for medical decision making (Ginzberg 1990; Binstock and Post 1991) further emphasize the importance of developing age-sensitive interventions that can maximize patient adaptation to both aging and cancerrelated losses.

The few studies that do compare middle-aged and older age groups find important differences in both medical and psychosocial domains (Prohaska et al 1985; Filipp 1992; Rose 1993; Clark-Plaskie and Lachmann 1999). For example, in comparing hospitalized advanced cancer patients, differences were found between middle-aged and older patients' preferences as well as end-of-life care practices and outcomes (Rose et al 2000, 2004). Indeed, comparisons between middle-aged and older advanced cancer patients can provide more precise information about potential unique problems and intervention effects in the earlier versus later stages of maturity. Thus, in assessing age differences in processes and outcomes of interventions, it is important to compare middle-aged patients in their forties and fifties (40-60) and young-old patients in their sixties and seventies (61-80). These two age groups, with slight variation in proposed age cut-points (eg, 60 vs 65), have been conceptualized as worthy of separate analysis in studies on adult development and health and disease in adulthood (Silliman et al 1997; Merluzzi and Nairn 1999; Merrill and Verbrugge 1999; Staudinger and Bluck 2001). In advanced cancer, the great majority $(>90 \%)$ of patients seeking treatment in tertiary cancer care are between 40 and 80 years old (Rose et al 2004).

Baltes and Baltes (1990) developed a theoretical model of successful aging that proffers selective optimization with compensation over the lifespan. According to this model, selection processes address the choice of goals, life domains, and life tasks whereas compensation and optimization are concerned with the means to maintain or enhance chosen goals overtime (Baltes and Carstensen 1999, p 218). Optimization involves a narrowing of goals and expectations that build on remaining strengths and capacities for realistic achievement. Compensation often requires intervention, as a response to loss in capacity to meet goals, can be automatic or planned and might require new skills (Baltes and Baltes 1990; Baltes 1997). Similarly, in advanced cancer, coping and adaptation often necessitates clarifying and shifting life goals and goals of care while simultaneously modifying strategies for optimization with compensation from the early treatment phase through end of life. As the disease progresses, patients may seek support in (1) refocusing on personal goals that are most valued and achievable and (2) compensating through medical care and practical supportive services that maximize achievement of goals, including home care and hospice (Mor et al 1987, 1992). These adaptive 
processes and needs for support may differ for older patients (eg, Rose 1993; Mor et al 1994).

\section{Psycho-oncology interventions for advanced cancer patients}

During the past several decades, numerous psycho-oncology interventions to reduce cancer patients' distress levels and improve coping skills have been tested (Rowland 1990; Fawzy et al 1995; Nezu et al 1998; Meyer and Mark 1999). The majority of these interventions involve structured, time-limited support groups or educational programs for patients, particularly in the early diagnosis and treatment phase of the disease. Psychooncology interventions primarily focus on patients' emotional and physical distress and coping abilities (Massie et al 1990; Fawzy et al 1995; Loscalzo and Brintzenhofeszoc 1998; Baum and Andersen 2001; Balducci and Beghe 2002). However an additional important goal for such interventions is to improve patients' ability to understand symptoms and treatment decisions and communicate their ongoing needs and preferences for support and care to their physicians. This is especially important given that previous interventions to improve physician decision making practices and patient quality of life outcomes have had minimal effect (eg, Support Principal Investigators 1995). Indeed, numerous studies indicate that seriously ill patients and their physicians continue to have difficulty communicating about poor prognoses and end-of-life care (Miyaji 1993,1994; Weeks et al 1998; Lynn et al 2000a, 2000b).

Lessons learned from the unsuccessful SUPPORT intervention, which involved nurse discussions with hospitalized patients and families about care decisions, have informed the development of more recent initiatives (SUPPORT Principal Investigators 1995; Lynn et al 2000a). For example, Joanne Lynn and her colleagues (2000b) made the following observations of factors that may have contributed to SUPPORT's ineffectiveness: (1) patients' preferences evolve as they confront new situations, and patients often find difficulty in fully articulating their wishes; (2) as the disease progresses, care situations are resolved in predictable ways and may go unmentioned as decision points; (3) patients and families often delay or dodge taking responsibility for making a choice, perhaps fearing uncertainty or subsequent regret; and (4) patients may behave in seemingly irrational ways, focusing on how they appear to loved ones, avoiding talk about death, and/or framing their experience in fatalistic or magical ways (p S215). Such behaviors have been well documented in cancer patients and are often described in terms of distress, coping and communication problems (Roland 1990; Grassi et al 1993; Davidson et al 1999).
The dynamic nature of coping and communication in late stage cancer patients (Davidson et al 1999; Nezu, Nezu, Houts, et al 1999; Folkman and Greer 2000) argues for interventions that support patients across conditions and settings, over time, and through illness progression as life circumstances and perspectives about goals of care evolve. Telephone interventions have had promise in this regard and models have been tested (Bucher et al 1998), ranging from structured, fairly brief interventions (Alter et al 1996; Nezu, Nezu, Friedman, et al 1999; Nezu, Nezu, Houts, et al 1999) to long term counseling interventions for early stage (Marcus et al 1998) or high risk/metastatic breast cancer patients (Donnelly et al 2000). Issues surrounding coping and communication behaviors are independent of late-stage cancer type. Thus, all patients with near end stage cancers may benefit from a coping and communication support intervention tailored to patient preferences.

\section{Aging and psycho-oncology interventions}

Psycho-oncology interventions appeal largely to patients who are middle-aged or younger adults (Massie et al 1990; Meyer and Mark 1999; Nezu, Nezu, Friedman, et al 1999). However, age is not specifically evaluated in most reviews of psycho-oncology interventions for adults (Massie et al 1990; Fawzy et al 1995). The fact that older patients report lower levels of distress is often interpreted as their having less need or urgency for coping and communication support (Grassi et al 1993; Nordin and Glimelius 1998; Schnoll et al 1998). This may potentially mask the unique problems that older patients experience (Harrison and Maguire 1995; Ganz 1997; Extermann 2002). Interventions typically have not been designed to accommodate preferences for engagement of different age groups, especially older adults.

Review of psycho-oncology and coping literature suggests several components that are key for a coping and communication support intervention tailored to advanced cancer patients over time: (1) initial screening for level of distress and related problems, including communication difficulties; (2) an in-home face-to-face care conference with a trained practitioner to set the stage for addressing coping and communication concerns of patients and family caregivers; (3) ongoing follow-up contact with a trained practitioner to address new stressors as well as to reappraise continuing coping and communication problems; and (4) multiple means of immediate access to the practitioner including phone and e-mail communication and requests for web-search guidance. These components have been tested in previous intervention studies, although no single study represents 
the full combination in programs for middle-aged and older advanced cancer patients.

Based on research linking distress with poor coping, care decision making and quality-of-life outcomes, The National Comprehensive Cancer Network (NCCN 1999) has recommended screening cancer patients of all ages for psychosocial distress and problems associated with distress (Zabora 1990). Anxiety and depression are associated with coping and communication problems, as well as with amplification of pain and other symptoms (Block 2000; McCarthy et al 2000). Anxiety in particular is linked to avoidance or blunting behaviors (Dunkel-Schetter et al 1992; Miller 1995; Miller et al 1996; Nordin and Glimelius, 1998) that can undermine contact and communication with physicians and/or family members. Indeed, middle-aged and older patients can be helped to understand the connection between their coping and communication behaviors (Ong et al 1999; Dowsett et al 2000) and this may be best accomplished using Miller's guidelines for tailoring psychosocial interventions to the individual's health information-processing style (Miller et al 2001). With a better understanding of one's own tendency to engage in monitoring and blunting behaviors in response to threatening health cues, patients may be helped to communicate more effectively with clinicians. Cancer patients' communication preferences (Rose 1990, 1993) can be important considerations in coaching patients on how to better interact with clinicians, especially as life goals and care goals may shift (Butow et al 1994; Tennstedt 2000). Communication problems with physicians differ by age group and may be difficult to detect or accurately assess in elderly patients (Ganz 1997; Adelman et al 2000; Nussbaum et al 2003).

Our coping and communication support intervention is tailored to the preferences of middle-aged and older advanced cancer patients and includes components suggested as essential by previous studies. It is based on three theoretical frameworks (see Figure 1 for our conceptual model). First, as in models of successful aging, coping and adaptation in advanced cancer involves a process of selecting and shifting personal life goals and goals of care while simultaneously developing strategies for optimization with compensation (ie, Baltes and Baltes 1990; Baltes 1997) from the early treatment phase through end of life. Second, communication in advanced cancer is affected by patients' health information processing style (ie, monitoring and blunting; Miller 1987, 1995) and understanding individual differences in attention to and avoidance of threatening health cues is key in developing strategies for more effective communication and decision making about goals over time. Third, the majority of middle-aged and older adults diagnosed with late-stage cancer have already adapted to a number of previous life changes and stresses. Consequently, patients in these mature age groups may be most responsive to a non-directive personcentered approach (Rogers 1951, 1967) in providing coping and communication support over time. It is anticipated that this tailored intervention may be associated with quality of care and quality of life in advanced cancer and with quality of care and quality of life outcomes at end of life.

\section{CCS intervention design and methods \\ Components of the CCS intervention}

This intervention is designed to be implemented with newly diagnosed late-stage cancer patients who are estimated to have a median life expectancy of one year or less. We enroll stage IV (or stage III lung or pancreatic) patients with the goal of establishing a supportive relationship and providing ongoing coping and communication support from the early treatment phase for late-stage cancer through end of life. The CCS intervention is being tested in a randomized controlled trial conducted in two ambulatory cancer clinics that provide care for the underserved patients are stratified by the two age groups and randomized to the intervention described in this paper or to a usual care control group. There are five components to this tailored CCS intervention for middle aged and older advanced cancer patients as outlined below.

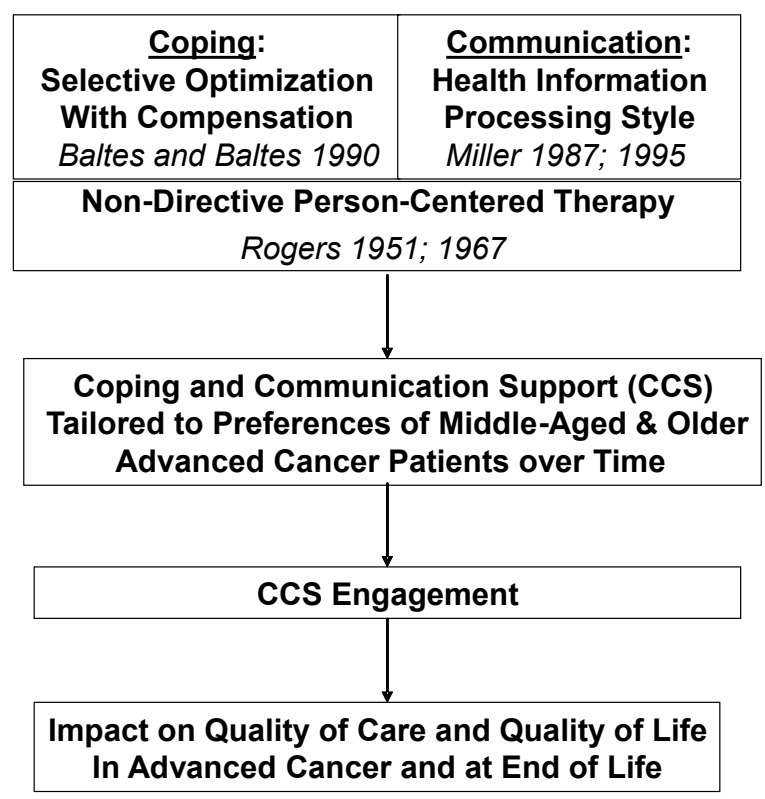

Figure I Conceptual framework. 


\section{Screening for distress and communication problems}

Newly diagnosed late-stage cancer patients who enroll in the study are first screened by clinic-based research staff for distress (distress thermometer), anxiety, depression, and problems associated with distress, using the 1999 NCCC guidelines. Patients randomized to the intervention are then called by a randomly assigned coping and communication support practitioner (CCSP; see below for a description of CCSPs) to schedule an in-home care conference. In this call, patients are encouraged to choose a family member (the person upon whom they most depend for support and assistance in care decision making) to participate in the care conference.

\section{Initial care conference}

A key feature of this intervention is the initial care conference to establish a connection between the patient and family member/s and the CCSP to set the stage for telephone follow-up. Whenever possible, this initial care conference occurs in the patient's home environment, thus allowing the CCSP to observe the relationship between patient and family and to assess the home and determine potential needs for practical assistance. During the conference, CCSPs review patient responses that were collected in the baseline interview about distress, including measures of anxiety and depression (POMS short form) (Sachman 1983) and health information processing style (Monitor-Blunter Style Scale - MBSS Short Form) (Steptoe 1989). The MBSS assesses patients' tendency to seek out information about threatening health cues (monitoring) and to seek distraction from threatening health cues (blunting) that can prompt discussion about (1) coping and communication issues, (2) strategies to address problems, and (3) concerns and expectations regarding illness and treatment. The CCSP also identifies patient preferences for their own engagement in the intervention (eg, type and frequency of contact) and how to include a family member in intervention follow-up. This is primarily a phone intervention available to patients 24 hours a day, 7 days a week. An initial schedule for follow-up phone contacts is set and amended by patients with each future contact.

During the initial care conference, the CCSP describes her goals for enhancing patient communication and shared decision making with healthcare team members, consulting about symptom management, and possibly facilitating patient contact with the physician, nurse/s, or social worker if needed. Patients are given a packet of information about the cancer clinic, potentially relevant community resources and how to contact CCSPs. To ensure that underserved patients have access to their CCSP, cell phones or a toll free phone number are provided for individuals who do not have home phones.

\section{CCS follow-up phone contacts}

Telephone interventions have been shown to be timely and efficacious for cancer patients (Alter et al 1996; Bucher et al 1998; Marcus et al 1998; Donnelly et al 2000). In this study, the schedule for telephone contacts is flexible and tailored to patient preference. Telephone contacts offer opportunities to: (1) explore the physical, emotional, functional and social impact of advanced cancer and its treatment; (2) prepare patients psychologically for future therapy or progression of disease; (3) identify personal goals and goals of treatment; (4) identify further needs for information/support; (5) enhance expression of affect; (6) support hope and appropriate psychological defense; (7) foster independence; (8) facilitate coping; (9) optimize social support; (10) address practical problems; and (11) refer patients for symptom management, informational needs, and support.

All patients receive a follow up phone call from their CCSP within two weeks following the introductory care conference to check on patient understanding and preferences for engagement. Patients who initially score 4 or more on the distress thermometer are specifically encouraged to receive monthly phone contacts from their CCSP to monitor distress. If distress remains high or worsens after the first phone contact, or if the patient has significant emotional or psychiatric symptoms, the CCSP consults with the more highly trained intervention coordinator about additional evaluation and potential referral for psychiatric services. No prearranged schedule is proposed for low distress patients (scores less than 4 on the distress thermometer) unless requested. These patients are encouraged to contact their CCSP as desired. The CCS intervention continues until the patient dies. If the patient is referred to hospice at any time, the patient and caregiver decide whether to continue contact with the CCSP.

At each contact, the CCSPs review patient concerns and/or communication issues, identify symptoms, and provide consultation and referral for patients regarding symptom management. Patients and families are referred to their physician or appropriate care provider when symptoms are perceived to require health care provider intervention. Patients' tendency to engage in monitoring and blunting in the context of threatening health cues is discussed with the patient to facilitate personal insight and develop strategies to address potential barriers in medical decision making (Miller 1995; Miller et al 2001). Discussions about patients' 
preferences for intervention (eg, role-playing situations, facilitating/participating in discussion with members of the healthcare team) may occur as well.

\section{CCS conjoint visit or health care team contacts}

The CCSP's role is to encourage direct communication between patient and physician. However, if patients are uncomfortable with this, the CCSP interacts with the physician and other members of the healthcare team in a facilitative role (with patient permission). The patient may request his/her CCSP to be present during a physician visit (conjoint visit) in the cancer clinic or to directly interact with the health care team. CCSP's knowledge of patients' information processing styles is helpful to promote effective communication between patients and healthcare providers. Suggestions made in earlier patient/health care contacts may be discussed and recommendations for supportive interventions (eg, nutrition, social work, home care) can be shared. In some instances, patients may prefer to meet face-to-face with their CCSP in the cancer clinic, while waiting for a scheduled appointment or treatment, although telephone calls are the primary mode of communication in the CCS intervention.

\section{E-mail access and web-guidance}

Patients with access to the internet may contact their CCSP by e-mail as well. E-mail/internet use in clinical practice is not without its challenges and we will explore its perceived usefulness and difficulties. Currently, older and underserved patients are less likely to use this mode of communication for information support (Davison et al 2000; Smyth et al 2007) and we expect this mode of contact to be fairly uncommon. In the introductory care conference, patients who have access to a computer and the internet are helped to determine how to utilize this aspect of the intervention eg, sending emails to CCSP and learning how to interpret or search for information on the web (Bucher and Houts 1999). Referrals for guided searches and perspectives on the accuracy of web-based information or recommendations are made to the American Cancer Society, the National Cancer Institute and reliable local sources.

\section{Problem domains identified and addressed in the CCS intervention}

Seven focal problem domains were identified from a review of the literature on coping and communication in advanced cancer. Specification of problem domains for interventions and quality improvement in palliative care is a useful example in this regard (NCP 2001). Our goal in addressing the problem areas described below is to foster effective coping and communication in maintaining or shifting life goals and care goals according to patient needs and preferences. Middle-aged and older adult patients may experience problems in any of the seven domains, although the frequency or extent of these problems may differ by age group over time. (Intervention strategies used to address these problems areas are described in a subsequent section of this paper).

\section{Psychological}

Assessment of psychological distress and well being is based on the premise that every patient at every stage of the cancer continuum experiences some degree of psychological distress (Holland 1999, 2000). It is estimated that approximately onethird of patients with cancer experience severe psychological distress (Derogatis et al 1983; Zabora et al 2001), with the prevalence of anxiety and depression being as high as $70 \%$ in advanced cancer (Kaasa et al 1993).

\section{Existential}

A study of concerns of the terminally ill (Greisinger et al 1997) found that coping with existential issues was the most important type of concern among more than $85 \%$ of patients with advanced cancer. Existential issues that threaten a person's intactness are experienced as one confronts one's mortality or the associated concerns regarding health, futility, meaningless, remorse, death related anxiety and disruption and engagement with and purpose in life (Kissane 2000). "Existential plight" is recognized as "a distinct phase of cancer to which almost all patients are subjected" (Weisman and Worden 1976, p 3) and is also a developmental issue with aging as patients reflect on the course of their lives (Nussbaum et al 2003).

\section{Communication with family and friends}

This problem area encompasses the relationship between patients and families, communication problems, satisfaction with relationships, etc. Patients and families need to relate on unique levels as the disease progresses and their relationship and communication patterns change. Patients with advanced cancer frequently identify communication with family and friends as a prominent concern (Greisinger et al 1997). This includes being able to express feelings, say goodbye, and know that family members will manage after death (Spiroch et al 2000). Stress in the patient/family member dyad can worsen if patients give up decision-making, become incapable of understanding the ramifications of decisions or stop 
communicating their wishes. A "conspiracy of silence" can develop as patients and family members attempt to protect each other from difficult emotions or conflicts (Rose and Haug 1999; Zhang and Siminoff 2003a). Patient-family discord about treatment decisions can be influenced by differing perceptions of stress and symptoms or goals for cancer care (Zhang and Siminoff 2003b; Siminoff, Rose, et al 2006). The CCS intervention can promote support and understanding between patients and family members in identifying symptoms, facilitating expression of feelings, and discussing patients' wishes for treatment goals.

\section{Communication with healthcare providers}

Communication issues with healthcare providers in advanced cancer can affect informed decisions about end-of-life care. Research on patient-physician communication indicates that patients continue to have unmet communication needs. Serious gaps in recall and understanding that can occur during psychological and physical health crises and differences in communication styles of providers and their underserved or older patients can complicate decision making (Siminoff, Graham, et al 2006). Indeed, the SUPPORT study (SUPPORT Principal Investigators 1995) determined that physicians and other healthcare professionals had an inaccurate understanding of symptoms and end-of-life wishes of patients with advanced disease. Additionally, patient preferences and needs for information can differ widely (Clayton et al 2005). Interventions to facilitate such ongoing communication and decision making with health care providers should be available at times when the patient most needs assistance in understanding and clarifying personal goals and treatment goals and concerns over time through the shifts that may occur in palliative care.

\section{Symptom management}

Epidemiologic studies have demonstrated that patients with advanced cancer (Walsh et al 2000), report a high prevalence of symptoms related to treatment or disease. Symptom distress is the strongest predictor of overall quality of life in people with advanced cancer (McMillan and Small 2002). The amount or level of physical or mental upset, anguish, or suffering experienced by a person differs depending on specific symptoms. For instance, patients experiencing pain are twice as likely to develop psychiatric complications as patients without pain (Derogatis et al 1983). As symptoms worsen with advanced disease, patients can benefit from opportunities to express concerns about specific symptoms and their management (Greisinger et al 1997). CCSPs may be able to help patients advocate for themselves with their health care providers about urgent or emergent symptom distress to obtain appropriate treatment.

\section{Practical concerns}

The financial burden on cancer patients has grown considerably, with many expenses related to cancer care being hidden costs, including insurance premiums, deductibles, copayments, transportation, lost income, and miscellaneous expenses (Wagner and Lacey 2004). These expenses can promote a barrier to comprehensive cancer care. Factors related to being underserved also may pose challenges in cancer care, including inadequate educational attainment and low literacy (Nielsen-Bohlman et al 2004), unemployment, substandard housing, chronic malnutrition, limited access to health care, and risk promoting lifestyles, attitudes and behaviors. Practical issues and concrete service needs require serious attention in a coping and communication intervention for advanced cancer patients (Mor et al 1987, 1992) and these needs are expected to differ by age group (eg, Mor et al 1994).

\section{Caregiver burden}

Advanced cancer patients may become concerned about being a burden to others. Such concerns may be triggered by the apparent impact on the personal time, social roles, physical and emotional states, and financial resources of family caregivers (Given et al 2001). With increased illness, patients may become concerned about the amount of time and difficulty of caregiving tasks, such as administering medical/nursing treatments, providing emotional support, assisting with activities of daily living, and arranging for medical treatment and follow ups (Bakas et al 2004). The CCS intervention is designed to assess and address patients concerns about burden, using a number of interventions strategies described below.

\section{Intervention strategies used in the CCS intervention}

Coping and communication support is provided through a variety of intervention strategies. Based on a review of this literature (eg, Andersen 1992; Meyer and Mark 1995) and applications to theoretical frameworks that inform our conceptual model (see Figure 1), we identified eight key strategies that may be used in the CCS intervention.

\section{Supportive listening}

As patients and caregivers experience treatments and symptoms associated with cancer, fears and psychological 
responses are common but can be difficult to express. The therapeutic value of expression of affect is demonstrated to be a mediating factor in the stress associated with cancer. Efforts to suppress sadness and other difficult emotions have been reported to increase dysphoric mood (Classen et al 1996) and are associated with poorer coping (Koopman et al 1998; Derogatis et al 1979). Supportive listening can facilitate facing life threatening issues directly and help patients shift from emotion-focused to problem-focused coping (Moos and Schaefer 1987) and can limit feelings of social isolation (Spiegel and Diamond 2001). Facilitating emotional expression modulates distress and prepares the individual to cope with current and future stressors.

\section{Education/handouts}

The value of knowledge in adjustment to illness is well established. Patients with advanced cancer have many questions about disease course, prognosis and treatments. An essential element of effective cancer treatment includes knowledge acquisition. Psycho educational interventions including discussing concerns, giving and receiving information, problem solving, coping skills training, facilitating expression of emotion and social support have been found to reduce depressive symptoms in patients with cancer (Barsevick et al 2002) and are beneficial to cancer patients in relation to pain (Devine 2003), and nausea and vomiting (Devine and Westlake 1995). In the CCS intervention, examples of educational topics include information and guidance about health system entry, cancer staging, helping patients understand when goals of care shift and whether decisions may be required, symptom management, utilizing information in approved sites, cancer therapy, and coping.

\section{Cognitive/problem-solving}

Cognitive behavioral approaches have empirical value in reducing and managing psychological distress in patients with cancer (Manne and Andrykowski 2006). For the purpose of the CCS intervention, cognitive therapy and problem solving will be separated from the behavioral interventions. This approach is based on the cognitive model, that the way situations are perceived influences emotions and includes problem solving and exploring automatic thoughts and coaching. Effective problem solving has been shown to reduce depression (Huibers et al 2003) and improve quality of life of cancer patients in preliminary findings (Nezu et al 1998). Exploring problems and coaching patients on effective identification and communication of the needs and goals of themselves, their families, friends and healthcare providers is key in this intervention.

\section{Validation}

The role of a helper in client-centered therapy is to assume the internal frame of reference of the client, to perceive the world as the client sees it, to perceive the client himself as he is seen by himself, and to communicate something of this empathic understanding to the client (Rogers 1951, $\mathrm{p} 29)$. The central hypothesis of this approach is that the individual has within him/herself vast resources for self understanding, for altering his/her self concept, attitudes, and self-directed behavior--and that these resources can be tapped if only a definable climate of facilitative psychological attitudes can be provided. Training in client-centered empathic communication includes nonverbal and verbal behaviors such as reflection, validation, support, partnership, and respect. Validation of the individual's position is perceived as accepting and is a useful intervention demonstrated by using statements expressing acceptance of the individual's views, or legitimizing a concern. The validation of patient concerns is useful as a technique to promote safety (Ellingson and Buzzanell 1999) and quality care for depressed patients.

\section{Case navigation}

It is important to clarify the meaning of case navigation as one strategy used in the CCS intervention, given the rapid growth in clinical use of "navigators" to improve cancer care (Dignan et al 2005; Dohan and Schrag 2005; Freeman 2006; Rayford 2006). The role of the navigator has been focused mostly on maximizing adherence to clinically accepted cancer screening and treatment protocols and minimizing perceived barriers to care (Schrag 2005). Alternatively, CCSPs take direction from the patient without access to medical information or formal connection to the clinic or physician group. In the CCS intervention, case navigation may involve coordinating transportation, providing outreach and education, arranging clinic appointments, facilitating reimbursement for services, bridging cultural and language differences between providers and patients, and providing emotional and social support according to patient preference. Mor and colleagues (1992) found with advanced cancer that older age and low income predicted a need for help with personal care and transportation. This intervention was designed to reduce the prevalence of unmet needs by helping patients access important services and resources within the healthcare system and in the community. 


\section{Behavioral}

Behavioral strategies in providing coping and communication support span guided imagery, relaxation training, music, distraction, role playing, and other broadly accepted complementary therapies involving behavioral change by the patient. The use of such behavioral interventions during cancer treatment has shown positive benefits in reducing anticipatory nausea, pain, and distress (Luebbert et al 2001; Redd et al 2001; Miller and Kearney 2004). Although complementary therapies have been less frequently pursued by the current cohort of older adults (Rose et al 1998), the potential benefit of such therapies in palliation could be similar for patients in this age group. Middle-aged and older patients will be informed of appropriate strategies and may be coached in behavioral interventions in facilitating coping.

\section{Web-based guidance}

Computer-based programs have been tested with underserved women with breast cancer and have shown value in improving competence in seeking information, participating in care, communicating with physicians, and obtaining social support (Gustafson et al 2001). Computer based nursing interventions providing information on symptoms and symptom management, emotional support and counseling for patients with newly diagnosed cancer and families has been shown to be effective in reducing depression and improving other measures of psychological health (Rawl et al 2002). Computer mediated communication systems have been utilized for support groups to reduce or eliminate the barriers to face-to-face support. Patients may need ongoing guidance in seeking or interpreting information and its credibility in the media and on the internet.

\section{Referral}

The CCS intervention is designed to supplement usual care in the oncology care setting. In the development of the NCCN Distress Management Guidelines (NCCN 2006), it was recognized that $1 / 3$ of cancer patients in the outpatient setting experienced significant distress and an even larger proportion of those with poorer prognosis experienced distress (Zabora et al 2001). A distress rating of 4 or greater results in referral to trained staff who explore the source of distress in more depth (NCCN 2006). Although this intervention may effectively address normal fears, worries, communication concerns, and practical needs, referral is a critical part of comprehensive care. Indeed, an important goal of this intervention is to help patients best communicate their needs and wishes to the staff involved in their care.

\section{Coping and communication support practitioners (CCSP)}

The role of the CCSP was developed to assist patients with advanced cancer to understand their options for treatment, communicate their needs regarding treatment and end-oflife decisions effectively, ensure resolution of practical issues through services/referrals, navigate the healthcare system for pain and symptom management and learn ways of coping with emotional and existential issues that often accompany the diagnosis and management of cancer and terminal illness. CCSPs are advanced practice nurses with either a master's degree in psychiatric/mental health or with other mental health training. Recruits to this position are screened for their experience with aging, cancer, and mental health; level of knowledge about coping and communication; commitment to the communication skills needed for this study; ability to accommodate to flexible hours; and comfort with allowing the client to ultimately control or chart their own course.

Given that CCSPs provide telephone access on a 24/7 schedule, it has been determined that a reasonable full-time caseload is $80-100$ clients, including patients and their family caregivers. By design, CCSPs rely on patients' perspectives and preferences; they do not have access to patient medical records. Challenges faced by CCSPs include not having access to records, 24/7 scheduling, the unpredictability of crises which may occur in multiplicity, and the unpredictable requests of high user clients who require frequent and lengthy contacts. In addition, working between the terminally ill who may present with poor resources and an overburdened health care system can be a significant stressor. Several techniques are utilized to mediate the workload stress. One is the weekly team care conferences where attendees provide expertise in medicine, geriatrics, palliative care and clinical ethics and in discussions of ethical concerns and difficult situations for problem-solving and support. The second is frequent opportunities to memorialize the deaths of patients and to recognize the impact of these deaths on the CCSP and team. In addition, the CCSPs keep weekly logs of their insights, most difficult challenges, and ideas about rapport-building with patients which are discussed with the CCS Intervention Coordinator for further exploration when needed.

CCSP training begins with an orientation to the three theoretical frameworks illustrated in Figure 1. They are 
instructed in applying the theory of successful aging as "selective optimization with compensation" to foster effective coping and adaptation among recently diagnosed latestage cancer patients through end of life. Special attention is given to theory and research on patient-doctor communication and decision making processes in cancer during the active treatment phase and at end of life. The CCSPs are taught the importance of health information processing styles and how to take into account patient scores on monitoring and blunting when coaching patients. They are informed in the use of Rogerian Client-Centered (Person-Centered) approach to establish therapeutic rapport with the patient. In that light, the goal of all interactions is a nondirective style toward facilitation of self-actualization, self-realization and helping the client to explore barriers to expressing goals for therapy and make appropriate decisions for treatment. As many patients express practical concerns, the CCSP is trained to help explore problems or may be asked to make calls and obtain services. In addition, the CCSP must provide brief therapies that foster relaxation, problem-solving, and coaching.

The CCSPs provide an important adjunctive role to the healthcare team in coaching, promoting and educating patients on new skills in communication, and assisting patients to optimize participation in their own health care experience. This role changes over time as the illness of the patient progresses, treatment fails, or as realization of possible death occurs. A detailed description of CCSP roles and responsibilities, training and methods to ensure fidelity of the CCS intervention are described by Radziewicz and colleagues (2007).

A critical responsibility of CCSPs is to document patient preferences, problem domains, intervention strategies and engagement in the CCS intervention. These data are essential to answer important questions about similarities and differences between middle-aged patients, in their 40s and 50s, and young-old advanced cancer patients, in their 60s and 70 s, who constitute the great majority of patients treated in tertiary care ambulatory cancer clinics. It is important to note that less than five percent of patients enrolled in this study are over age 80 and, although these patients are also randomized to the intervention, this old-old age group (eg, Rose et al 2004) will be separately analyzed at the end of the study period.

The CCSPs document patient engagement in the intervention from the initial care conference to patients' death. A password protected web-accessible database was specifically designed to document each contact with the patient. For the initial care conference, data are entered about the context (setting and length), problem domains identified and patient preferences for engagement, including frequency, mode (phone, cancer clinic, email) and directionality (initiation by CCSP, patient or family) of follow up contact. Similarly, for every follow up contact, data are entered about mode and directionality of communication, problem domains raised, intervention strategies used and any changes in preference for contact. Patient engagement in the intervention over time is examined to determine the frequency and length of contacts as well as in the problem domains raised and types of intervention strategies used after the initial care conference. In this paper, we report data on middle-aged (ages 40-60; $\mathrm{N}=82$ ) and young-old (ages 61-80; $\mathrm{N}=79$ ) patients who were enrolled and randomized to the intervention, who participated in an initial care conference and had access to the intervention for a minimum of six weeks after the initial care conference. These data represent patterns of engagement for patients enrolled during the first half of a four-year recruitment period in the CCS intervention study.

\section{Patient engagement in the CCS intervention Profile of middle-aged and young-old advanced cancer patients Demographic characteristics}

Advanced cancer patients in the two age groups were not significantly different on the majority of demographic characteristics (see Table 1). The majority of patients enrolled in the two cancer clinics and randomized to the CCS intervention were male, had annual incomes below \$20,000, and had a high school education. Middle-aged patients were more likely than older patients to be unmarried, uninsured or on Medicaid only, indicating that this population may be especially vulnerable in coping with the diagnosis and treatment of late-stage cancer.

\section{Physical and psychosocial status}

Patients' physical status, psychosocial status and health information processing style were assessed at baseline. Table 2 includes a brief profile of patient characteristics in these areas by patient age group. Physical status was assessed in a count of comorbidities documented in chart reviews and standardized measures of physical symptom distress and functional limitations. The 13-item symptom distress scale (McCorkle and Young, 1978) was administered during the initial screen for distress and limitations in activities of daily 
Table I Advanced cancer patients' demographic characteristics at intake

\begin{tabular}{|c|c|c|c|c|c|}
\hline & \multicolumn{2}{|l|}{$\begin{array}{l}\text { Middle-age } \\
40-60 \text { years } \\
n=82\end{array}$} & \multicolumn{2}{|l|}{$\begin{array}{l}\text { Young-old } \\
61-80 \text { years } \\
n=79\end{array}$} & \multirow[t]{2}{*}{ p-value } \\
\hline & $\mathbf{N}$ or mean & $(\%$ or $s d)$ & $\mathbf{N}$ or mean & (\% or sd) & \\
\hline \multicolumn{6}{|l|}{ Age } \\
\hline Mean age (sd) & 53.40 & 5.26 & 68.51 & 6.02 & 0.000 \\
\hline \multicolumn{6}{|l|}{ Gender } \\
\hline Male & 51 & $62.0 \%$ & 59 & $74.7 \%$ & 0.094 \\
\hline Female & 31 & $37.8 \%$ & 20 & $25.3 \%$ & \\
\hline \multicolumn{6}{|l|}{ Race } \\
\hline White & 40 & $48.8 \%$ & 50 & $63.3 \%$ & 0.131 \\
\hline African American & 38 & $46.3 \%$ & 28 & $35.4 \%$ & \\
\hline Other & 4 & $4.9 \%$ & I & $1.3 \%$ & \\
\hline \multicolumn{6}{|l|}{ Income* } \\
\hline$\$ 0-\$ 9,999$ & 21 & $26.3 \%$ & 16 & $22.2 \%$ & 0.167 \\
\hline$\$ 10,000-\$ 14,999$ & 14 & $17.5 \%$ & 20 & $27.8 \%$ & \\
\hline$\$ 15,000-\$ 19,999$ & 8 & $10.0 \%$ & 15 & $20.8 \%$ & \\
\hline$\$ 20,000-\$ 29,999$ & 15 & $18.8 \%$ & 9 & $12.5 \%$ & \\
\hline$\$ 30,000-\$ 39,999$ & 8 & $10.0 \%$ & 7 & $9.7 \%$ & \\
\hline$\$ 40,000-\$ 49,999$ & 6 & $7.5 \%$ & 2 & $2.8 \%$ & \\
\hline$\$ 50,000$ or more & 8 & $10.0 \%$ & 3 & $4.2 \%$ & \\
\hline \multicolumn{6}{|l|}{ Marital status } \\
\hline Single & 18 & $22.0 \%$ & 2 & $2.5 \%$ & $<0.0001$ \\
\hline Married/Partner & 28 & $34.1 \%$ & 43 & $54.4 \%$ & \\
\hline Separated/Divorced & 31 & $37.8 \%$ & 24 & $30.4 \%$ & \\
\hline Widowed & 5 & $6.1 \%$ & 10 & $12.7 \%$ & \\
\hline \multicolumn{6}{|l|}{ Formal education } \\
\hline Mean Years (sd) & 12.32 & 2.3 & 12.33 & 2.5 & 0.975 \\
\hline \multicolumn{6}{|l|}{ Insurance } \\
\hline Medicare only & 4 & $4.9 \%$ & 9 & $11.4 \%$ & 0.155 \\
\hline Medicaid only & 36 & $43.9 \%$ & 15 & $19.0 \%$ & 0.000 \\
\hline Private health insurance & 15 & $18.3 \%$ & 17 & $21.5 \%$ & 0.694 \\
\hline Medicare + medicaid & 8 & $9.8 \%$ & 22 & $27.8 \%$ & 0.004 \\
\hline Medicare + private insurance & I & $1.2 \%$ & 10 & $12.7 \%$ & 0.004 \\
\hline Not insured & 18 & $22.0 \%$ & 6 & $7.6 \%$ & 0.024 \\
\hline
\end{tabular}

*Sample size varies due to missing values

living (ADLs) (Katz et al 1963) and instrumental activities of daily living (IADLs) (Fillenbaum 1988) were measured in baseline interviews. Psychosocial status was measured on the distress thermometer (NCCN 1999) and on anxiety and depression subscales of the Profile of Mood Scale (POMS, Short Form) (Sachman 1983) administered during the initial screen for distress. Health Information Processing Style was assessed with the Miller Monitoring and Blunting ScaleAbbreviated Version (Miller 1987; Steptoe 1989) in baseline interviews with patients.

As shown in Table 2, there were significant differences between middle-aged and young-old advanced cancer patients in co-morbid conditions, symptom distress, and psychosocial status but not in functional status or health information processing style. Whereas young-old patients had more documented co-morbidities, middle-aged patients reported more physical symptoms and emotional distress and experienced higher levels of anxiety and depression than the older patients. In terms of health information processing style, patients in both age groups had higher scores in monitoring than in blunting.

\section{Patient preferences and engagement in the CCS intervention \\ Preliminary findings on the initial care conference}

The context of patients' initial care conference was similar for the two age groups, including the agreed upon setting and actual length of these meetings (see Table 3 ). Although there were no significant differences in these variables, it is important to note a tendency for more 
Table 2 Advanced cancer patients' physical and psychosocial characteristics

\begin{tabular}{|c|c|c|c|c|c|}
\hline & \multicolumn{2}{|c|}{$\begin{array}{l}\text { Middle-age } \\
40-60 \text { years } \\
n=82\end{array}$} & \multicolumn{2}{|c|}{$\begin{array}{l}\text { Young-old } \\
61-80 \text { years } \\
n=79\end{array}$} & \multirow[t]{2}{*}{ p-value } \\
\hline & mean & (sd) & mean & $(\mathbf{s d})$ & \\
\hline \multicolumn{6}{|l|}{ Physical status } \\
\hline Total comorbid conditions & 1.35 & 1.5 & 2.01 & 1.6 & 0.007 \\
\hline Symptom distress scale & 30.28 & 9.1 & 24.98 & 6.5 & 0.001 \\
\hline \multicolumn{6}{|l|}{ Possible range $13-52$} \\
\hline \multicolumn{6}{|l|}{ Functional status } \\
\hline ADL limitations & 0.99 & 1.3 & 0.73 & 1.2 & 0.199 \\
\hline \multicolumn{6}{|l|}{ Possible range: $0-7$} \\
\hline IADL limitations & 2.78 & 3.2 & 1.99 & 3.2 & 0.124 \\
\hline \multicolumn{6}{|l|}{ Possible range: $0-21$} \\
\hline \multicolumn{6}{|l|}{ Psychosocial status } \\
\hline Distress thermometer & 4.99 & 2.8 & 3.49 & 2.7 & 0.001 \\
\hline \multicolumn{6}{|l|}{ Possible range: $0-10$} \\
\hline POMS anxiety & 9.01 & 6.4 & 5.64 & 5.3 & 0.000 \\
\hline \multicolumn{6}{|l|}{ Possible range: $0-24$} \\
\hline POMS depression & 10.41 & 8.6 & 5.72 & 6.8 & 0.000 \\
\hline \multicolumn{6}{|l|}{ Possible range: $0-32$} \\
\hline \multirow{2}{*}{\multicolumn{6}{|c|}{$\begin{array}{l}\text { Health information processing } \\
\text { style (MBSS short form) }\end{array}$}} \\
\hline & & & & & \\
\hline MBSS monitoring & 5.32 & 1.8 & 5.06 & 1.9 & 0.408 \\
\hline \multicolumn{6}{|l|}{ Possible range: $0-8$} \\
\hline MBSS blunting & 3.85 & 1.8 & 3.72 & 1.7 & 0.631 \\
\hline Possible range: $0-8$ & & & & & \\
\hline
\end{tabular}

middle aged patients to prefer meeting in the cancer clinic versus their own home. These initial care conferences lasted approximately an hour and a half for patients in both age groups. On average, patients in both age groups were first seen within their fourth month following a diagnosis of late-stage cancer and virtually all patients identified one or more problems during the initial care conference (see Table 4). Symptom management and psychological and practical aspects of coping were the most prevalent problems raised by both age groups. More middle aged than young-old patients raised problems in communicating with family/friends about their disease and/or treatment decision making. The great majority of patients preferred that the CCSP take the initiative in follow up contacts, primarily by phone and on a weekly to monthly basis.

Table 3 Context of initial care conference

\begin{tabular}{|c|c|c|c|c|c|}
\hline & \multicolumn{2}{|l|}{$\begin{array}{l}\text { Middle-age } \\
40-60 \text { years } \\
n=82\end{array}$} & \multicolumn{2}{|l|}{$\begin{array}{l}\text { Young-old } \\
61-80 \text { years } \\
n=79\end{array}$} & \multirow[t]{2}{*}{ p-value } \\
\hline & $\mathbf{N}$ or mean & (\% or sd) & $\mathbf{N}$ or mean & (\% or sd) & \\
\hline \multicolumn{6}{|l|}{ Setting of initial care conference } \\
\hline Patient's home & 43 & $54.4 \%$ & 50 & $64.9 \%$ & 0.308 \\
\hline Family member's home & 8 & $10.1 \%$ & 7 & $9.1 \%$ & \\
\hline Cancer clinic* & 20 & $25.3 \%$ & 11 & $14.3 \%$ & \\
\hline Other location in hospital* & 5 & $6.3 \%$ & 8 & 10.4 & \\
\hline Other** & 3 & $3.8 \%$ & 1 & $1.3 \%$ & \\
\hline \multicolumn{6}{|l|}{ Length of initial conference } \\
\hline Mean minutes (sd) & 92.7 & 40.3 & 92.4 & 42.8 & 0.964 \\
\hline \multicolumn{6}{|c|}{ Weeks from diagnosis to initial care conference } \\
\hline Mean weeks (sd) & 14.5 & 11.7 & 16.3 & 14.5 & 0.406 \\
\hline
\end{tabular}


Table 4 Advanced cancer patients' problems and preferences in initial care conference

\begin{tabular}{|c|c|c|c|c|c|}
\hline & \multicolumn{2}{|c|}{$\begin{array}{l}\text { Middle-age } \\
40-60 \text { years } \\
n=82\end{array}$} & \multicolumn{2}{|c|}{$\begin{array}{l}\text { Young-old } \\
61-80 \text { years } \\
n=79\end{array}$} & \multirow[t]{2}{*}{ p-value } \\
\hline & $\mathbf{N}$ & $(\%)$ & $\mathbf{N}$ & (\%) & \\
\hline \multicolumn{6}{|l|}{ Problems domains raised in initial care conference* } \\
\hline Respondents who identified one or more problems & 80 & $97.6 \%$ & 76 & 96.3 & 0.490 \\
\hline \multicolumn{6}{|l|}{ Number of patients (\%) who identified problems } \\
\hline Symptom issues & 77 & $96.3 \%$ & 72 & $93.5 \%$ & 0.490 \\
\hline Psychological problems & 67 & $82.7 \%$ & 61 & $77.2 \%$ & 0.433 \\
\hline Practical problems & 66 & $81.5 \%$ & 54 & $68.4 \%$ & 0.068 \\
\hline Communication with family/friends & 49 & $60.5 \%$ & 26 & $32.9 \%$ & 0.000 \\
\hline Existential Problems & 45 & $55.6 \%$ & 48 & $60.8 \%$ & 0.525 \\
\hline Communication with health care providers & 41 & $50.6 \%$ & 49 & $62.0 \%$ & 0.155 \\
\hline Caregiver Burden & I & $1.2 \%$ & 2 & $2.5 \%$ & 0.618 \\
\hline \multicolumn{6}{|c|}{ Patient preferences for follow-up engagement in the intervention } \\
\hline \multicolumn{6}{|l|}{ Preference for follow-up initiator, $\mathrm{N}$ (\%) } \\
\hline Patient & 6 & $7.4 \%$ & 6 & $7.7 \%$ & 0.664 \\
\hline Family caregiver & 0 & $0.0 \%$ & 2 & $2.6 \%$ & \\
\hline CCS practitioner & 70 & $86.4 \%$ & 64 & $82.1 \%$ & \\
\hline Other** & 5 & $6.2 \%$ & 6 & $7.7 \%$ & \\
\hline \multicolumn{6}{|l|}{ Preference for follow-up method, N (\%) } \\
\hline Phone & 76 & $95.0 \%$ & 73 & $94.8 \%$ & 0.410 \\
\hline In person & 3 & $3.8 \%$ & I & $1.3 \%$ & \\
\hline E-mail & I & $1.3 \%$ & 3 & $3.9 \%$ & \\
\hline \multicolumn{6}{|l|}{ Preference for follow-up frequency, $\mathrm{N}$ (\%) } \\
\hline Daily & 2 & $2.5 \%$ & 0 & $0.0 \%$ & 0.522 \\
\hline Two or three times each week & 3 & $3.8 \%$ & 3 & $3.9 \%$ & \\
\hline Weekly & 22 & $27.5 \%$ & 15 & $19.5 \%$ & \\
\hline Every two weeks & 36 & $45.0 \%$ & 36 & $46.8 \%$ & \\
\hline Monthly & II & $13.8 \%$ & 17 & $22.1 \%$ & \\
\hline Other** & 6 & $7.5 \%$ & 6 & $7.8 \%$ & \\
\hline
\end{tabular}

*Missing values for I respondent.

**Unsure, as needed, not often.

Preliminary findings on engagement in the intervention, problems identified and strategies used in the first six weeks following the initial care conference

There was a non-significant trend of middle-aged patients engaging in more follow-up contacts and of greater variability in their engagement. The majority of patients in both age groups had at least three follow up contacts with CCSPs within the first six weeks after the initial care conference. The majority of patients had weekly to monthly contacts and over 90 percent of these contacts occurred by phone with the great majority initiated by the CCSP, as originally preferred by patients (see Table 5).

As indicated in Table 6, the pattern of problems most frequently raised during follow up contacts was similar to the initial care conference, with symptom, practical, and psychological problems being most common. However, there were more age group differences in problem domains raised during follow up contacts, with more middle-aged patients raising practical and existential concerns in addition to problems communicating with family/friends about their disease or treatment goals. In both age groups, symptoms were raised in approximately $80 \%$ of follow up contacts. There were no apparent age-group differences in the intervention strategies used during follow up contacts. In both age groups the three most commonly used strategies in the early weeks of follow up contact were supportive listening, education/handouts and cognitive problem solving.

\section{Discussion of findings on patient engagement in the CCS intervention}

This paper has described the CCS intervention and reported preliminary findings on the similarities and differences between middle-aged and young-old patients' patterns of initial engagement in the intervention. As anticipated, the demographic profile of advanced cancer patients in this intervention 
Table 5 Characteristics of patient contacts in first six weeks after initial care conference

\begin{tabular}{|c|c|c|c|c|c|}
\hline \multirow[b]{2}{*}{ Contacts } & \multicolumn{2}{|l|}{$\begin{array}{l}\text { Middle-age } \\
40-60 \text { years } \\
n=82\end{array}$} & \multicolumn{2}{|l|}{$\begin{array}{l}\text { Young-old } \\
61-80 \text { years } \\
n=79\end{array}$} & \multirow[t]{2}{*}{ p-value } \\
\hline & $\mathbf{N}$ or mean & (\% or $\mathrm{sd})$ & $\mathbf{N}$ or mean & (\% or sd) & \\
\hline \multicolumn{6}{|l|}{ Number of patient contacts } \\
\hline Mean number of contacts (sd) & 3.83 & 4.4 & 2.97 & 2.3 & 0.129 \\
\hline (Range) & $(I-28)$ & $(I-12)$ & & & \\
\hline \multicolumn{6}{|l|}{ Length of contacts } \\
\hline Mean number of minutes (sd) & 10.63 & 9.1 & 9.85 & 10.9 & 0.640 \\
\hline \multicolumn{6}{|l|}{ Frequency of patient contacts } \\
\hline$>12$ Contacts (eg, daily), N (\%) & 2 & $2.4 \%$ & 0 & $0.0 \%$ & 0.375 \\
\hline 8-12 Contacts ( $2 / 3$ per week), N (\%) & 3 & $3.7 \%$ & 3 & $3.8 \%$ & \\
\hline 5-7 Contacts (weekly), N (\%) & 20 & $24.4 \%$ & 15 & $19.0 \%$ & \\
\hline 3-4 Contacts (bi-weekly), N (\%) & 20 & $24.4 \%$ & 21 & $26.6 \%$ & \\
\hline I-2 Contacts (monthly), N (\%) & 28 & $34.1 \%$ & 36 & $45.6 \%$ & \\
\hline 0 Contacts (eg, other), N (\%) & 9 & $11.0 \%$ & 4 & $5.1 \%$ & \\
\hline \multicolumn{6}{|l|}{ Proportion of contacts by mode } \\
\hline Phone, mean (sd) & 0.91 & 0.19 & 0.92 & 0.21 & 0.742 \\
\hline Clinic visit, mean (sd) & 0.08 & 0.19 & 0.08 & 0.21 & 0.637 \\
\hline E-Mail, mean (sd) & 0.01 & 0.06 & 0.00 & 0.00 & 0.312 \\
\hline \multicolumn{6}{|l|}{ Proportion of contacts by initiator } \\
\hline CCS practitioner, mean (sd) & 0.89 & 0.24 & 0.82 & 0.33 & 0.105 \\
\hline Patient, mean (sd) & 0.05 & 0.17 & 0.11 & 0.27 & 0.082 \\
\hline Family caregiver, mean (sd) & 0.02 & 0.09 & 0.01 & 0.06 & 0.438 \\
\hline Other, mean (sd) & 0.02 & 0.06 & 0.02 & 0.12 & 0.823 \\
\hline
\end{tabular}

was representative of populations treated in ambulatory cancer clinics that provide care for the underserved. The majority of patients in both age groups reported annual incomes below $\$ 20,000$ and typically had a high school education. Because one of the two ambulatory cancer clinics in this study was in a Veterans Affairs Medical Center, it is not surprising that the majority of patients in both age groups were male. The finding that approximately $40 \%$ of patients were African American was expected, given that African Americans are the largest underserved minority group in the region. Middle-aged patients were especially vulnerable, given that more of these patients were unmarried and without medical insurance.

Consistent with findings in previous studies of advanced cancer patients, middle-aged patients reported higher levels of physical and emotional distress than older patients, including greater depression and anxiety. In contrast, as expected, older patients had more documented co-morbidities, averaging two conditions in addition to their cancer. The finding that most advanced cancer patients in both age groups were not experiencing significant functional limitation is consistent with previous literature, and may in part be explained by the fact that patients were only recently diagnosed and that older patients were young-old versus old-old. There was no age group difference in patients' health information processing style, considered to be a stable characteristic of individuals. The finding that patients in both age groups had higher scores in monitoring than in blunting style will require further analyses to understand its meaning and implications. Given past and present data on older patients' lower distress ratings and their relatively low rates of participation in previous psycho-oncology programs, an important question here was whether older patients would need or chose to engage in CCS intervention and in what ways.

Patients randomized to the CCS intervention were contacted by a CCSP by phone to arrange the initial faceto-face care conference, preferably in the patient's home. Although there were no significant age group differences in the agreed upon setting, it appears that older patients may be more willing to allow a home visit. On average, these initial care conferences take about an hour and a half to establish rapport and assess the patient's overall situation, including initial coping and communication problems and preferences for follow-up contact. Although our ultimate goal is to implement this type of intervention as soon as possible after a diagnosis is made, the lag time from diagnosis to the initial care conference associated with this being a randomized clinical trial was longer than would be expected if implemented as usual care in cancer clinics. The majority of 
Table 6 Problem domains raised and intervention strategies used in first six weeks after initial care conference

\begin{tabular}{|c|c|c|c|c|c|}
\hline & \multicolumn{2}{|c|}{$\begin{array}{l}\text { Middle-age } \\
40-60 \text { years } \\
n=82\end{array}$} & \multicolumn{2}{|c|}{$\begin{array}{l}\text { Young-old } \\
61-80 \text { years } \\
n=79\end{array}$} & \multirow[t]{2}{*}{ p-value } \\
\hline & $\overline{\mathbf{N}}$ & (\%) & $\overline{\mathbf{N}}$ & (\%) & \\
\hline \multicolumn{6}{|l|}{ Problems identified in first six weeks } \\
\hline Respondents who identified one or more problems & 69 & $84.1 \%$ & 72 & $91.1 \%$ & 0.234 \\
\hline \multicolumn{6}{|c|}{ Number of respondents (\%) who identified specific problems } \\
\hline Symptom issues & 63 & $76.8 \%$ & 65 & $84.8 \%$ & 0.233 \\
\hline Practical problems & 51 & $62.2 \%$ & 31 & $39.2 \%$ & 0.005 \\
\hline Psychological problems & 41 & $50.0 \%$ & 31 & $39.2 \%$ & 0.205 \\
\hline Communication with health care providers & 27 & $32.9 \%$ & 27 & $34.2 \%$ & 0.869 \\
\hline Communication with family/friends & 27 & $32.9 \%$ & $\mathrm{II}$ & $13.9 \%$ & 0.005 \\
\hline Existential problems & 25 & $30.5 \%$ & 14 & $17.7 \%$ & 0.067 \\
\hline Caregiver burden & 1 & $1.2 \%$ & 0 & $0.0 \%$ & - \\
\hline \multicolumn{6}{|l|}{ Interventions used in first six weeks } \\
\hline \multicolumn{6}{|c|}{ Number of patients (\%) for whom each intervention strategy was used } \\
\hline Supportive listening & 69 & $84.1 \%$ & 71 & $89.9 \%$ & 0.352 \\
\hline Cognitive/problem solving & 50 & $61.0 \%$ & $4 I$ & $51.9 \%$ & 0.269 \\
\hline Education/handouts provided & 47 & $58.0 \%$ & 45 & $58.4 \%$ & 1.000 \\
\hline Validation* & 17 & $20.7 \%$ & 17 & $21.5 \%$ & 1.000 \\
\hline Case navigation & 15 & $18.3 \%$ & 13 & $16.5 \%$ & 0.837 \\
\hline Referral & 15 & $18.3 \%$ & 7 & $8.9 \%$ & 0.108 \\
\hline Behavioral & 14 & $17.1 \%$ & 8 & $10.1 \%$ & 0.253 \\
\hline Web guidance** & 0 & $0.0 \%$ & 0 & $0.0 \%$ & - \\
\hline
\end{tabular}

*This strategy was added to documentation after the first year of enrollment, based on observed need.

** $17 \%$ of middle-aged and $22 \%$ of young-old patients reported having access to the internet.

patients enrolled were receiving at least one form of active treatment (ie, chemotherapy, radiation or surgery).

In the initial care conference, virtually all middle-aged and young-old patients raised at least one problem area of concern, primarily related to symptoms, psychological or practical issues. At the outset, middle-aged patients reported more problems in communicating with family and friends about their cancer or treatment decisions. Neither age group expressed concerns about being a burden to family, at least during this early treatment phase. Although older patients had reported less physical and psychosocial distress at intake, their preferences for engagement in the intervention were very similar to those of middle-aged patients. Indeed, the great majority of patients in both age groups preferred to have contact on a weekly to monthly basis, conducted primarily by phone, with the CCSP initiating contact. This is the first study to document older cancer patients' initial preferences for a tailored coping and communication support intervention. As it turns out, their preferences are similar to those of middle-aged advanced cancer patients.

Patterns of actual engagement during the first six weeks following the care conference were consistent with initial preferences and did not differ by age group. On average, patients had three to four contacts lasting approximately
10 minutes each and most of these were phone calls initiated by the CCSP. Although generally in keeping with initial preferences for weekly to monthly contact, patients' original preferences appear to represent a slight overestimation of contacts sought during subsequent weeks. As in the initial care conference, the most common problem domains raised by patients in follow up contacts were related to symptoms, practical and psychological issues. The finding that more middle-aged than young-old patients raised practical or existential concerns and problems in communicating with family and friends provides important insight into the potential unique challenges faced by patients in this age group. Regardless of these age group differences in the prevalence of certain problem domains, the CCSPs used similar intervention strategies with the two groups.

The common use of supportive listening underlines the goals of this non-directive CCS intervention tailored to the ongoing needs and preferences of patients. Cognitive/problemsolving and educational support strategies also were used with the majority of patients in both age groups. Although validation was not originally conceptualized as a distinct intervention strategy, it has proven to be an important one in more recent documentation with approximately half of the patients in this sample. Attention to behavioral strategies, including the use 
of complementary therapies was reported only for $14 \%$ of middle-aged and $8 \%$ of older patients during this early treatment phase. Finally, although $17 \%$ of middle-aged and $22 \%$ of young-old patients reported having some form of access to the internet, these patients did not engage by email and CCSPs did not report providing web guidance to such patients in either age group during the initial six weeks of contact.

In conclusion, to our knowledge, this CCS intervention is the first psycho-oncology intervention specifically designed to be age sensitive and to examine age-group differences in engagement from the early treatment phase for late-stage cancer through end of life. The intervention was designed to facilitate older patients' access to and engagement in the intervention based on their own preferences for coping and communication support over time. With this in mind, the development of this intervention was informed by theory and research on successful aging (Baltes and Baltes 1990; Baltes 1997), health information processing style (Miller1995; Miller et al 2001) and non-directive client-centered therapy (Rogers 1951, 1961, 1967). Preliminary data on middle-aged and older patients indicate that older patients raise similar problems and voice similar preferences for engagement in the intervention, regardless of the fact that their baseline physical and emotional distress levels were lower. Older patients also did not differ from middle-aged patients in their level of engagement, key problems faced and intervention strategies used during the first six weeks of follow up contact. However, the finding that more middle-aged than young-old patients raised problems in communicating with family and friends and practical and existential concerns as well in follow up contacts provides important insight into the potentially unique coping and communication challenges faced by patients in the two age groups.

This intervention study will continue to enroll patients for another full year and will test hypotheses about age group differences in quality of care and quality of life outcomes for patients in the CCS intervention versus usual care control arms, from the early treatment phase after a diagnosis of advanced cancer through end of life. It is anticipated that this project will contribute to knowledge about processes and outcomes of the intervention for middle-aged and young-old advanced cancer patients who constitute the great majority of advanced cancer patients diagnosed and treated in ambulatory cancer clinics that provide care to the underserved. This age-sensitive and tailored intervention is expected to affect quality of care and quality of life outcomes for patients over time. Research findings will guide plans to modify and disseminate this intervention.

\section{Funding sources}

National Cancer Institute: R01-CA10282, VHA HSR\&D Merit: IIR-03-255, American Cancer Society: ROG-04-09001. We wish to acknowledge our intervention staff (Rose Anne Berila and Amy Spuckler) and research staff (Mary Ellen Lawless, Anthony D’Eramo, Mary Hutchinson, Nasim Seifi) on this Project.

\section{References}

American Cancer Society, [ACS]. 2006. Facts and figures. American Cancer Society, Atlanta, GA.

Adelman RD, Greene MG, Ory MG. 2000. Communication between older patients and their physicians. Clin Geriatr Med, 16:1-24.

Alter CL, Fleishman SB, Kornblith AB, et al. 1996. Supportive telephone intervention for patients receiving chemotherapy - a pilot study. Psychosomatics, 37:425-31.

Andersen BL. 1992. Psychological interventions for cancer patients to enhance the quality of life. J Consult Clin Psychol, 60:552-68.

Bakas R, Austin JK, Jessup SL, et al. 2004. Time and difficulty of tasks provided by family caregivers of stroke survivors. J Neurosci Nurs, 36:95-106.

Balducci L, Beghe C. 2002. Management of cancer in the older person. Clin Geriatr, 10:54-60.

Baltes PB. 1997. On the incomplete architecture of human ontogeny: Selection, optimization and compensation as foundation of developmental theory. Am Psychol, 52:366-80.

Baltes PB, Baltes MM. 1990. Successful aging: perspectives from the behavioral sciences. New York: Cambridge University Press.

Baltes MM, Carstensen LL. 1999. Social-psychological theories and their applications to aging: From individual to collectiveIn Bengston VL, Schaie KW eds. Handbook of theories of aging. NY: Springer Publishing, p 299-226.

Barsevick AM, Sweeney C, Haney E, et al. 2002. A systematic qualitative analysis of psychoeducational interventions for depression in patients with cancer. Oncol Nurs Forum, 29:73-84.

Baum A, Andersen BL. 2001. Psychosocial intervention and cancer. In: Baum A, Anderson BL eds. Psychosocial interventions for cancer. Washington DC: American Psychological Association, p 3-12.

Binstock RH, Post SG. 1991. Old age and the rationing of health care. In: Binstock RH, Post SG eds. Too old for health care? Baltimore: Johns Hopkins University Press, p 1-12.

Block SD. 2000. Assessing and managing depression in the terminally ill patient ACP-ASIM end-of-life care consensus panel. Ann Intern Med, 132:209-18.

Bucher JA, Houts PS. 1999. Problem-solving through electronic bulletin boards. J Psychosoc Oncol, 16:85-91.

Bucher JA, Houts PS, Glajchen M, et al. 1998. Telephone counseling. In: Holland JC ed. Psycho-oncology. New York: Oxford University Press, p 758-66.

Butow PN, Dunn SM, Tattersall MHN, et al. 1994. Patient participation in the cancer consultation: evaluation of a question prompt sheet. Ann Oncol, 5:1999-204.

Clark-Plaskie M, Lachman ME. 1999. The sense of control in midlife. In: Willis SL, Reid JD. eds. Life in the middle psychological and social development in middle age. San Diego: Academic Press, p 181-208.

Classen C, Koopman C, Angell K, et al. 1996. Coping styles associated with psychological adjustment to advanced breast cancer. Health Psychol, 15:434-7.

Clayton JM, Butow PN, Tattersall MHN. 2005. The needs of terminally ill cancer patients versus those of caregivers for information regarding prognosis and end-of-life issues. Cancer, 103:957-1964.

Cleary JF, Carbone PP. 1997. Palliative medicine in the elderly. Cancer, 80:1335-47. 
Coe RM, Miller DK. 2000. Communication between the hospitalized older patient and physician. Clin Geriatr Med, 16:109-18.

Davison KP, Pennebaker JW, Dickerson SS. 2000. Who talks? The social psychology of illness support groups. Am Psychol, 55:205-17.

Davidson JR, Brundage MD, Feldman-Stewart D. 1999. Lung cancer treatment decisions: Patients' desires for participation and information. Psychooncology, 8:511-20.

Derogatis LR, Morrow GR, Fetting J, et al. 1983. The prevalence of psychiatric disorders among cancer patients. JAMA, 249:751-7.

Derogatis LR, Abeloff MD, Melisartos N. 1979. Psychological coping mechanisms and survival time in metastatic breast cancer. JAMA, 242:1504-8.

Devine EC. 2003. A meta-analysis of the effect of psychoeducational interventions in pain on adults with cancer. Oncol Nurs Forum, 30:75-89.

Devine EC, Westlake SK. 1995. The effects of psychoeducational care provided to adults with cancer: Meta-analysis of 116 studies. Oncol Nurs Forum, 22:1369-81.

Dignan MB, Burhansstipanov L, Hariton J, et al. 2005. Cancer control, 12 Suppl 2:28-33.

Distress Treatment Guidelines for Patients, Version 1. 2005, National Comprehensive Cancer Network and American Cancer Society.

Dohan D, Schrag D. 2005. Using navigators to improve care of underserved patients: current practices and approaches. Cancer, 104:848-55.

Donnelly JM, Kornblith AB, Fleishman S, et al. 2000. A pilot study of interpersonal psychotherapy by telephone with cancer patients and their partners. Psychooncology, 9:44-56.

Dowsett SM, Saul JL, Butow PN, et al. 2000. Communication styles in the cancer consultation: Preferences for a patient-centered approach. Psychooncology, 9:147-56.

Dunkel-Schetter C, Feinstein LG, Taylor SE, et al. 1992. Patterns of coping with cancer. Health Psychol, 11:79-87.

Ellingson LL, Buzzanell PM. 1999. Listening to women's narratives of breast cancer treatment: a feminist approach to patient satisfaction with physician-patient communication. Health Commun, 11:153-83.

Esper P, Hampton JN, Finn J, et al. 1999. A new concept in cancer care. The supportive care program. Am J Hosp Palliat Care, 16:713-22.

Extermann A. 2002. Cancer in the older patient: a geriatric approach. Ann of Long-Term Care, 10:49-54.

Fawzy FI, Fawzy NW, Arndt LA, et al. 1995. Critical review of psychosocial interventions in aging. Arch of Gen Psychiatry, 52:100-13.

Filipp S-H. 1992. Could it be worse? The diagnosis of cancer as a prototype of traumatic life eventsIn Montada L, Filipp S-H, Lerner MJ vs . Life crises and experiences of loss in adulthood. Hillsdale, NJ: Lawrence Erlbaum Associates, Publishers, p 23-56.

Fillenbaum GG. 1988. Multidimentional functional assessment of older adults. Hillsdale, NJ: Erlbaum

Folkman S, Greer S. 2000. Promoting psychological well-being in the face of serious illness: When theory, research and practice inform each other. Psychooncoloogy, 9:11-19.

Freeman HP. 2006. Patient navigation: a community centered approach to reducing cancer mortality. J Cancer Edu, 21:S11-14.

Ganz PA. 1997. Interaction between the physician and the older patientThe oncologist's perspective. Cancer, 80:1270-2.

Ganz PA, Schag CC, Heinrich RL. 1985. The psychosocial impact of cancer on the elderly: A comparison with younger patients. $J$ Am Geriatr Soc, 33:429-35.

Ginzberg E. 1990. High-tech medicine and rising health care costs. JAMA, 263:1820-2.

Given B, Kozachik S, Collins C, et al. 2001. Caregiver role strain. In Maas M, Buckwalter K, Hardy M, et al ( vs ). Nursing care of older adult diagnoses: outcome and interventions. St. Louis, MO: Mosby, p 679-95.

Grassi L, Rosti G, Lasalvia A, et al. 1993. Psychosocial variables associated with mental adjustment to cancer. Psychooncology, 2:11-20.

Greisinger A, Lorimor R, Aday L, et al. 1997. Terminal ill cancer patients. Their most important concerns. Cancer Pract, 5:147-54.
Gustafson DH, Hawkins R, Pingree S, et al. 2001. Effect of computer support on younger women with breast cancer. J Gen Intern Med, $16: 435-45$.

Hamel ME, Teno JM, Goldman L, et al. 1999. Patient age and decisions to withhold life-sustaining treatments for seriously ill, hospitalized adults. Ann Intern Med, 130:116-25.

Harrison J, Maguire P. 1995. Influence of age on psychological adjustment to cancer. $J$ Psychosoc Oncol, 4:33-8.

Haug M, Ory M. 1997. Issues in elderly patient-provider interactions. Research on Aging, 9:3-44.

Holland JC. 1999. NCCN practice guidelines for the management of psychosocial distress. Oncology, 13:113-47.

Holland JC. 2000. An algorithm for rapid assessment and referral of distressed patients. In Perry MC (ed). American Society of Clinical Oncology Educational Book. Alexandria, VA: American Society of Clinical Oncology, p 129-38.

Huibers MJ, Beurskens AJ, Bleijenberg G, et al. 2003. The effectiveness of psychosocial interventions delivered by general practitioners. The Cochrane Database of Systematic Reviews (Online), (2): CD003494.

Kaasa S, Malt U, Hagen S, et al. 1993. Psychological distress in cancer patients with advanced disease. Radiother Oncol, 27:193-7.

Katz S, Ford AB, Moskowitz RW, et al. 1963. Studies of illness in the aged. The index of ADL: A standardized measure of biological and psychological function. JAMA, 185:914-19.

Kissane DW. 2000. Psychospiritual and existential distress: the challenge for palliative care. Aust Fam Physician, 29:1022-5.

Koopman C, Hermanson K, Diamond S, et al. 1998. Social support, life stress, pain and emotional adjustment to advanced breast cancer. Psychooncology, 7:101-11.

Loscalzo M, Brintzenhofeszoc K. 1998. Brief crisis counseling. In Holland JC (ed). Psycho-oncology. New York: Oxford University Press, p 662-75.

Luebbert K, Dahme B, Hasenbring M. 2001. The effectiveness of relaxation training in reducing treatment-related symptoms and improving emotional adjustment in acute non-surgical cancer treatment: a metaanalytical review. Psychooncology, 10:490-502.

Lynn J, Arkes HR, Stevens M, et al. 2000. Rethinking fundamental assumptions: SUPPORT's implications for future reform. $J$ Am Geriatr Soc, 48:S214-21.

Lynn J, DeVries KO, Arkes HR, et al. 2000. Ineffectiveness of the SUPPORT intervention: review of explanations. $J$ Am Geriatr Soc, 48: S206-13.

Manne SL, Andrykowski MA. 2006. Are psychological interventions effective and accepted by cancer patients?II Using empirically supported therapy guidelines to decide. Ann Behav Med, 32:98-103.

Marcus AC, Garrett KM, Cella D, et al. 1998. Telephone counseling of breast cancer patients after treatment: A description of a randomized clinical trial. Psychooncology, 7:470-82.

Massie MJ, Holland JC, Straker N. 1990. Psychotherapeutic Interventions. In Holland JC, Rowland JR eds. Handbook of psycho-oncology: psychological care of the patient with cancer. New York: Oxford University Press, $\mathrm{p}$ 455-69.

McCarthy EP, Phillips RS, Zhong Z, et al. 2000. Dying with cancer: patients' function, symptoms, and care preferences as death approaches. $J \mathrm{Am}$ Geriatr Soc, 48:S110-21.

McCorkle R, Young K. 1978. Development of a symptom distress scale. Cancer Nurs, 10:373-8.

McMillan SC, Small BJ. 2002. Symptom distress and quality of life in patients with cancer newly admitted to hospice home care. Oncol Nurs Forum, 29:1421-8.

Merluzzi TV, Nairn RC. 1999. Adulthood and aging: transitions in health and health cognition. In Life-span perspectives on health and illness. Mahwah, NJ: Lawrence Erlbaum Assoc. Inc., Publishers, p 189-206.

Merrill SS, Verbrugge LM. 1999. Health and disease in midlife. In Willis SL, Reid JD eds. Life in the middle. San Diego: Academic Press, p 77-103. 
Meyer TJ, Mark MM. 1999. Effects of psychosocial interventions with adult cancer patients: a meta-analysis of randomized experiments. In: Suinn RM, VandenBos GR eds. Cancer patients and their families. Washington DC: American Psychological Association, p 163-77.

Miller M, Kearney N. 2004. Chemotherapy-related nausea and vomitingPast reflections, present practice and future management. Eur J Cancer Care, 13:71-81.

Miller SM. 1987. Monitoring and blunting: validation of a questionnaire to assess styles of information seeking under threat. J Pers Soc Psychol, 52:345-53.

Miller SM. 1995. Monitoring versus blunting styles of coping with cancer influence the information patients want and need about their disease. Cancer, 76:167-77.

Miller SM, Rodoletz M, Schroeder CM, et al. 1996. Applications of the monitoring process model to coping with severe long-term medical threats. Health Psychol, 15:216-25.

Miller SM, Fang CY, Diefenbach MA, et al. 2001. Tailoring psychosocial interventions to the individual's health information processing style: the influence of monitoring versus blunting in cancer risk and disease. In Baum A, Anderson BL (eds). Psychosocial interventions for cancer. Washington, DC: American Psychological Association, p 343-62.

Miyaji NT. 1993. The power of compassion: truth-telling among American doctors in the care of dying patients. Soc Sci Med, 36:249-64.

Miyaji NT. 1994. Informed consent, cancer, and truth in prognosis (letter). N Engl J Med, 331:810.

Moos RH, Schaefer JA. 1987. The crisis of physical illness: an overview and conceptual approach. In Moos RH (ed). Coping with physical illness: Vol. 2. New Perspectives. New York: Plenum, p 3-25.

Mor V, Allen SM, Siegel K, et al. 1992. Determinants of need and unmet need among cancer patients residing at home. Health Services Research, 27:337-60.

Mor V, Allen S, Malin M. 1994. The psychosocial impact of cancer on older versus younger patients and their families. Cancer, 74 (7 Suppl):2118-27.

Mor V, Guadagnoli E, Wool M. 1987. An examination of concrete service needs of advanced cancer patients. J Psychosoc Oncol, 5:1-17.

National Comprehensive Cancer Network, [NCCN]. 1999. Practice guidelines for the management of psychosocial distress. Oncology, 13:113-47.

National Comprehensive Cancer Network, [NCCN]. 2006. NCCN clinical practice guidelines in oncology ${ }^{\mathrm{TM}}$ : distress management, version 1. August 2006.

[NCP] National Concensus Project. 2001. Clinical practice guidelines for quality palliative care. The National Consensus Project for Quality Palliative Care (NCP) [online]. Accessed January 17, 2007. URL: http://www.nationalconsensusproject.org

Nezu AM, Nezu C, Friedman S, et al. 1998. Helping cancer patients cope: a problem-solving approachWashington, D.C. American Psychological Association

Nezu AM, Nezu CM, Houts PS, et al. 1999. Relevance of problem-solving therapy to psychosocial oncology. J Psychosoc Oncol, 16:5-26.

Nezu CM, Nezu AM, Friedman SH, et al. 1999. Cancer and psychological distress: Two investigations regarding the role of social problemsolving. J Psychosoc Oncol, 16:27-41.

Nielsen-Bohlman L, et al (eds). 2004. Health literacy: a prescription to end confusion. Washington D.C: The National Academies Press, Institute of Medicine

Nordin K, Glimelius B. 1998. Reactions to gastrointestinal cancer-variation in mental adjustment and emotional well-being over time in patients with different prognoses. Psychooncology, 7:413-23.

Nussbaum JF, Baringer D, Kundrat A. 2003. Health, communication and aging: cancer and older adults. Health Communication, 15:187-94.

Ong LML, Visser MRM, Van Zuuren FJ, et al, 8. 1999. Cancer patients' coping styles and doctor-patient communication. Psychooncology, 155-66.

Prohaska TR, Leventhal EA, Leventhal H, et al. 1985. Health practices and illness cognition in young, middle aged, and elderly adults. J Gerontol, 40:569-78.
Radziewicz R, Rose JH, O'Toole E, et al. 2007. Assessing treatment fidelity in a "navigator" coping and communication support intervention for advanced cancer patients. Psychooncology, 16:53.

Rawl SM, Given BA, Given CW, et al. 2002. Intervention to improve psychological functioning for newly diagnosed patients with cancer. Oncol Nurs Forum, 29:967-75.

Rayford W. 2006. Managing the low-socioeconomic-status prostate cancer patient. J Natl Med Assoc, 98:521-30.

Redd WH, Montgomery GH, DuHamel KN. 2001. Behavioral intervention for cancer treatment. J Natl Cancer Inst, 93:810-23. Accessed January 29, 2007. URL: http://jnci.oxfordjournals.org/cgi/content/ full/93/11/810

Rogers CR. 1951. Client-centered therapy. London: Constable and Robinson LTD.

Rogers CR. 1961. On becoming a person. Boston: Houghton Mifflin.

Rogers CR (ed). 1967. The therapeutic relationship and its impact Madison: University of Wisconsin Press.

Rose JH. 1990. Social support and cancer: Adult patients' desire for support from family, friends, and health professionals. Am J Community Psychol, 18:439-64.

Rose JH. 1991. A life course perspective on health threats in aging. J Gerontol Soc Work, 17:85-97.

Rose JH. 1993. Interactions between patients and providers: an exploratory study of age differences in emotional support. J Psychosoc Oncol, $10: 43-67$.

Rose JH, O’Toole E, Skeist R, et al. 1998. Complementary therapies for older patients: an exploratory survey of primary care physicians' attitudes. Clin Gerontologist, 19:3-19.

Rose JH, Haug M. 1999. Book review: communication and the cancer patient: Information and truth. J Ethics Law Aging, 5:71-3.

Rose JH, O'Toole E, Dawson NV, et al. 2000. Age differences in care practices and outcomes for hospitalized patients with cancer. $\mathrm{J} \mathrm{Am}$ Geriatr Soc, 48(Suppl 5):S25-S32.

Rose JH, Bowman KF, Deimling G. 2004. Health maintenance activities and lay decision-making support: a comparison of young-old and old-old long-term survivors. J Psychosoc Oncol, 22:21-44.

Rose JH, O'Toole EE, Dawson NV, et al. 2004. Perspectives, preferences, care practices and outcomes among older and middle-aged patients with late-stage cancer. Am J Clin Oncol, 22:4907-17.

Rowland JH. 1990. Intrapersonal resources: coping. In Holland JC, Rowland JR (eds). Handbook of psycho-oncology: psychological care of the patient with cancer. New York: Oxford University Press, p 44-57.

Sachman E. 1983. A shortened version of the Profile of Mood States. J Pers Assess, 47:305-6.

Schrag D. 2005. Using navigators to improve care of underserved patients: current practices and approaches. Cancer, 104:848-55.

Schnoll RA, Harlow LL, Stolbach LL, et al. 1998. A structural model of the relationships among stage of disease, age, coping, and psychological adjustment in women with breast cancer. Psychooncology, 7:69-77.

Siegler EL, Levin BW. 2000. Physician-older patient communication at the end of life. Clin Geriatr Med, 16:175-204.

Silliman RA, Troyan SL, Guadagnoli E, et al. 1997. The impact of age, marital status and physician-patient interactions on the care of older women with breast carcinoma. Cancer, 80:1326-33.

Siminoff LA, Graham GC, Gordon NH. 2006. Cancer communication patterns and the influence of patient characteristics: disparities in information-giving and affective behaviors. Patient Educ Couns, 62:355-60

Siminoff LA, Rose JH, Zhang A, et al. 2006. Measuring discord in treatment decision-making: Progress toward development of a cancer communication and decision-making assessment tool. Psychooncology, 15:528-540.

Smyth K, Rose JH, McClendon MJ, et al. 2007. Relationships among caregivers' demographic characteristics, social support ratings, and expectations of computer-mediated support groups. J Applied Gerontol, $26: 58-77$ 
Spiegel D, Diamond S. 2001. Psychosocial interventions in cancer: group therapy techniques. In Baum A, Andersen BL (eds). Psychosocial interventions for cancer. Washington D.C.: American Psychological Association.

Spiroch C, Walsh D, Mazanec P, et al. 2000. Ask the patient: a semi-structured interview study of quality of life in advanced cancer. Am J Hosp Palliat Care, 17:235-40.

Staudinger UM, Bluck S. 2001. A view on midlife development from lifespan theory. In Lachman ME (ed). Handbook of midlife development. New York: John Wiley and Sons, p 3-39.

Steptoe A. 1989. An abbreviated version of the Miller Behavioral Style Scale. Br J Clin Psychol, 28:183-4.

SUPPORT Principal Investigators. 1995. A controlled trial to improve care for seriously ill hospitalized patients: The Study to Understand Prognoses and Preferences for Outcomes and Risks of Treatments (SUPPORT). JAMA, 274:1591-8.

Tennstedt SL. 2000. Empowering older patients to communicate more effectively in their medical encounter. Clin Geriatr Med, 16:61-70.

Wagner L, Lacey MD. 2004. The hidden costs of cancer care. Clin J Oncol Nurs, 8:279-87.
Walsh D, Donnelly S, Rybicki L. 2000. The symptoms of advanced cancer: relationship to age, gender, and performance status in 1,000 patients. Support Care Cancer, 8:175-9.

Weeks JC, Cook FC, O’Day SJ, et al. 1998. Relationship between cancer patients' predictions of prognosis and their treatment preferences. $J$ Am Med Assoc, 279:1709-14.

Weisman AD, Worden JW. 1976. The existential plight in cancer: significance of the first 100 days. Int $J$ Psychiatry Med, 7:1-15.

Yancik R. 1997. Cancer burden in the aged: an epidemiological and demographic overview of cancer. Cancer, 80:1273-83.

Zabora JR. 1990. Screening procedures for psychosocial distress. In Holland JC, Rowland JR (eds). Handbook of psychooncology: psychological care of the patient with cancer. New York: Oxford University Press, p 653-61.

Zabora J, BrintzenhofeSzoc K, Curbow B, et al. 2001. The prevalence of psychological distress by cancer site. Psychooncology, 10:19-28.

Zhang A, Siminoff L. 2003a. Silence and cancer: why do families and patients fail to communicate?. Health Commun, 15:415-29.

Zhang AY, Siminoff LA. 2003b. The role of the family in treatment decision making by patients with cancer. Oncol Nurs Forum, 30:1022-8. 
